\title{
Optimization of process and conditions for enhanced xylanase production under SSF using inexpensive agro-industrial waste
}

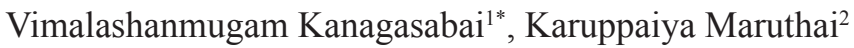 \\ ${ }^{1}$ Lecturer in Polymer/Plastic Technology, Tamilnadu Govt Polytechnic College, Madurai, India \\ ${ }^{2}$ Bioprocess Laboratory, Department of Chemical Engg., Annamalai University, Cuddalore, India
}

\section{ARTICLE INFO \\ Article history: \\ Received on: February 14, 2021 \\ Accepted on: April 14, 2021 \\ Available online: September 01, 2021}

Key words:

Aspergillus fumigatus, central composite design, response surface methodology, sugarcane bagasse, xylanase

\begin{abstract}
The usage of agricultural wastes for enzymes production is considered an essential part in any approach to accomplish goals to reduce environmental pollution and disposal of waste. In the present investigation, xylanase enzyme production by Aspergillus fumigatus using agro-industrial waste sugarcane bagasse with solid state fermentation was studied by keeping the best possible values of process variables, substrate concentration, temperature, incubation time, initial moisture content, and initial $\mathrm{pH}$ of the medium. The above-mentioned variables affecting the fermentation conditions were optimized using response surface methodology (RSM). To estimate individual and interaction effects, the central composite design was used. The most favorable process variables attained were substrate concentration $=9.88 \mathrm{~g}$, temperature $=35.73^{\circ} \mathrm{C}$, incubation time $=120.05$ hours, initial moisture content $=71.30 \%$, and initial $\mathrm{pH}=4.98$. From analysis of variance, an $R^{2}$-value of 0.9848 signifies a good agreement between the experimental and predicted values for sugarcane bagasse. Also, the fitness of the model is confirmed by a high $R^{2}$-value. The RSM shows that xylanase activity of 417.521 $\mathrm{IU} / \mathrm{gds}$ was achieved for the optimized process environment. In addition to xylanase activity, a poor quantity of carboxy methyl cellulase activity was also recorded. This study is carried out for cost-effective xylanase production by using agro-industrial waste as cheaper carbon source. It can reduce environment pollution and also minimizes the cost for disposal of industrial waste.
\end{abstract}

\section{INTRODUCTION}

Industrial enzymes have expanding markets as they have the potential to be employed as biocatalysts in different industrialized segments for fresh functions which create requirements for enzymes with new performance and enhanced consistency. Commercially, the production of enzymes has significantly developed all through the past century. Among the currently known 4,000 enzymes, around 200 enzymes are used for commercial production [1]. The enzyme market had a value of $\$ 4.9$ billion for the production of commercial enzymes in 2015 and $4.7 \%$ annual growth rate was expected for the years 2016-2021 [2]. The approximate sharing of xylanase enzyme is expected to attain $\$ 500$ million by 2023 [3]. In recent years, great attention is attained for xylanase because

*Corresponding Author

Vimalashanmugam Kanagasabai, Lecturer in Polymer/Plastic Technology, Tamilnadu Govt Polytechnic College, Madurai, India. E-mail: vimalashanmugam@gmail.com of its extensive use in industrial biotechnological applications of this enzyme, mostly for the conversion of hemicellulose to xylose, pharmaceuticals, textile and leather, agricultural waste treatment, ethanol, and clarification of juices and wines [4].

The enzyme xylanase degrades $\beta-1,4$ xylan by cleaving $\beta-1,4$ glycosidic linkages and shapes utilizable products like xylose and xylobiose [5]. The joint action of enzymes, xylanases, and $\beta$-xylosidize for hydrolyzing main chain and additional enzymes like $\alpha$-arabinofuranosity, acetyl xylan esterase, $\alpha$-glucuronosity, and feruloyl esterase for hydrolyzing its branches is required for complete hydrolysis of xylan [6]. Researchers focus their attention on microbial enzymes because of its exploitation in commercial and biotechnological applications. Due to their accessibility, structural strength, and simple genetic manipulation, the xylanase production uses microbes other than animal and plant sources [7].

A prospective means of interest in acquiring enzymes is solid state fermentation (SSF). Compared with submerged fermentation, the 
SSF technique using solid substrate has a great advantage, owing to the absence of water to facilitate natural environment for growth of microorganisms, lowering investment expenditure, higher efficiency, and ease of further purification steps [8]. Industrially, commercial xylan as a solid medium that induce enzyme synthesis is not profitable and, therefore, inexpensive and readily available agro-wastes such as sugarcane bagasse, groundnut cake, and rice bran rich in xylan content should be preferred as substrates for xylanase production [9]. Through the rising development of agroindustrialized activities worldwide, wastes of huge capacities are produced per annum. In India, about 625 million tons of agroindustrial wastes are produced annually [10]. The exploitation of agro-industrialized waste materials for high-value enzyme synthesis is satisfactory due to the decreasing cost for the disposal of wastes [1].

Due to sugarcane bagasse's instant accessibility at sugar-processing industries, it is exploited to create added incomes by making the most of it for the production of enzymes [11]. Sugarcane bagasse is employed as a low-priced carbon resource for growth of fungal cultures. In addition, it has also been employed as a good enzyme inducer. At the industrial scale, microorganisms such as fungi, bacteria, and actinomycetes are used for xylanase production [12], but fungi are of immense importance [13]. Filamentous fungi are mainly interesting in view of the fact that they secrete enzymes into the culture media and their enzymatic activity level is significant in comparison with bacteria and yeasts. For the production of xylanase from wastes, filamentous fungi, including Aspergilli and Trichoderma, are extensively used [14] and they can produce enzymes via SSF. In SSF systems, xylanase production is usually reported using mostly Aspergillus species.

Several factors that significantly influence fungal enzymes production during fermentation comprise substrate concentration, incubation time, $\mathrm{pH}$, moisture content, and temperature, which must be optimized for higher productivity [9]. To meet the industrial requirements, more interest is fixed on the stability of the enzyme over various experimental conditions, as well as its ability to hydrolyze xylans [13].

Due to the interlinking nature of the process parameters, the interaction effects between the variables will not be considered while studying each factor alone or grouped with other factors. Hence, usual one factor at a time (OFAT) optimization approach might not subsist consistently [15]. An attractive approach for xylanase production is to cut down the unnecessary steps and treatments to shorten the fermentation time and decrease the production costs by choosing experimental design methods. The statistical optimization method such as central composite design (CCD) of response surface methodology (RSM) is used for the enhancement of process parameters for enzyme synthesis. It results in superior action when compared to the usual methods of the OFAT approach [16]. RSM includes benefits from the usual technique which identifies the relationship among the two self-determining factors that are accountable for superior enzyme production [17]. The mutual effect of all the self-regulating variables and its exchanges would be completely analyzed by RSM during the fermentation process.
Therefore, taking into consideration the significance and applications of xylanases in industries, the current research is carried out to make the most effective use of the process environment for xylanase enzyme synthesis from sugarcane bagasse as the one and only carbon supply for the fungal strain Aspergillus fumigatus under SSF.

\section{MATERIALS AND METHODS}

\subsection{Substrate Preparation and Microorganism}

Sugarcane bagasse was obtained from a local agricultural field near Chidambaram. It was then sun-dried for a 3-week period, powdered, sieved through 100-mesh screen, treated with $0.2 \mathrm{~N} \mathrm{NaOH}$ alkali solution, and used as a substrate. The collected substrate was placed in an oven at $50^{\circ} \mathrm{C}$ for 48 hours to remove the moisture content and stored for further use. The microorganism employed in the present study was $A$. fumigatus [Microbial Type Culture Collection and Gene Bank (MTCC) 343; ITCC2550], obtained from MTCC, Institute of Microbial Technology, Chandigarh, India.

\subsection{Inoculum Preparation}

The stock cultures were preserved as slants of the agar medium at $5^{\circ} \mathrm{C}$ and sub-cultured at an interval of 3 months and incubated for 120 hours at $35^{\circ} \mathrm{C}$. After incubation, $10 \mathrm{ml}$ of sterile water was added to the slants and the spores were removed using a sterile inoculation needle. The spores were shifted from the slants to Czapek Dox broth and incubated for 5 days at $35^{\circ} \mathrm{C}$. This spore suspension after filtration through a muslin cloth was used as the inoculum $(2-3 \mathrm{ml})$.

\subsection{Xylanase Production Under SSF}

SSF experiment was conducted in $250 \mathrm{ml}$ capacity Erlenmeyer flasks by varying the experimental conditions, such as substrate conc., $\mathrm{pH}$, initial moisture content, and incubation time according to the experimental design. The contents were thoroughly mixed and autoclaved at $121^{\circ} \mathrm{C}$ and 15 psi pressure for 15 minutes. After cooling, the inoculation was carried out using $5 \%(v / v)$ of the filtered inoculum.

All the experimental runs were carried out in duplicates and the samples were collected after 100 hours. The flasks were removed and by adding $50.0 \mathrm{ml}$ of $0.05 \mathrm{M} \mathrm{Na}$-citrate buffer ( $\mathrm{pH} 5.3$ ), the contents were mixed at $200 \mathrm{rpm}$ using an orbital shaker for a period of 30 minutes at room temperature. The extraction was conducted by pressing the flask contents using a cotton cloth. It was centrifuged at a speed of $15,000 \mathrm{rpm}$ for 20 minutes and the top clearest content was investigated for xylanase activity.

\subsection{Enzyme Assay}

Xylanase assay was carried out by assessing the quantity of reducing sugar according to the dinitrosalicylic acid (DNS) method [18] with D-xylose as standard. Xylanase production was stated as IU/g of dry substrate (IU/gds).

Carboxy methyl cellulase (CMcase) was analyzed by evaluating the reducing sugar content according to the DNS method [18] with D-glucose as the standard. 


\subsection{Optimization of Process Conditions}

A CCD experimental design with 10 star points, $\left(2^{5}=32\right)$ axial points, and eight replicates at the center point $\left(n_{0}=8\right)$, which results in 50 runs covering the complete spectrum of combination of variables, was designed for predicting a response surface. These 50 runs were carried out at different combinations of the five independent variables. At five different levels $(-2.38,-1,0,1$, and 2.38 ), the five independent variables were tested. The levels and range of self-regulating variables are presented in Table 1 and the 50 runs which were carried out are presented in Table.2.

The experiments runs with various substrate concentrations, temperature, $\mathrm{pH}$ values, moisture content, and incubation time were carried out at the same time covering the whole spectrum of combination of variables with a wide range for xylanase production in the CCD. 50 experiments were carried out out as a batch process as given in CCD (Table 2). The entire 50 runs were carried out thrice and the response is taken from the average of these values.

The values of the process parameters in the coded form were given by the following equation:

$p_{l}=\frac{P_{l}-P_{0}}{\Delta P_{l}}$

where $p_{1}$ is the $l$ th variables coded form, $p_{1}$ is the $l$ th test variable uncoded form, and $p_{0}$ is the center point $l$ th test variable uncoded form. The span and extent of the experimental parameters are shown in Table 1.

The investigational design is shown in Table 2. The data were subjected to variance analysis and were fitted using the following second-order polynomial equation:

$Z=\beta_{0}+\sum_{l=1}^{n} \beta_{m} P_{m}+\sum_{l=1}^{n} \beta_{m} P_{m}^{2}+\sum_{l=1, l<m}^{n-1} \sum_{m=2}^{k n} \beta_{l m} P_{l} P_{m}$

where $Z$ is the predicted xylanase activity, $\beta_{l}, \beta_{m}$, and $\beta_{l m}$ are constants assessed from regression. They represent the linearized, quadratic, and interaction effects of $A, B, C, D$, and $E$ on xylanase activity.

The data obtained were subjected to regression analysis using the statistical analysis software Design Expert 8.0.7.1.5 and the constants of Eq. (2) were estimated. The statistical tests called analysis of variance (ANOVA) was employed for validation of the regression equation.

\section{RESULTS AND DISCUSSION}

From the second-order polynomial Eq. (2), the response xylanase activity was related to the five independent variables by using the multiple regression analysis and statistical importance of the constants of Eq. (2) were evaluated using Design Expert 8.0.7.1.5. The correlation between the five dependent variables and xylanase activity is elucidated as follows:

Xylanase activity, $\mathrm{Z}(\mathrm{IU} / \mathrm{gds})=415.017-5.318 A+5.973 B-$ $1.862 C+3.208 D+6.319 E+10.815 A^{*} B+9.188 A^{*} C-3.028$ $A^{*} D-0.602 A^{*} E+3.068 B^{*} C+0.355 B^{*} D+8.286 B * E+$ $4.911 C^{*} D+1.261 C^{*} E-4.236 D^{*} E-15.088 A^{2}-12.411$ $B^{2}-15.818 C^{2}-9.797 D^{2}-14.427 E^{2}$

where $Z$ is the xylanase activity and $A, B, C, D$, and $E$ were symbolic codes of substrate concentration, temperature, initial $\mathrm{pH}$, initial moisture content, and incubation time, correspondingly.

Experimental and predicted xylanase activity values are given in Table 2. The testing of variance (ANOVA) was made to analyze the results and is presented in Table 3 . The significance is specified by ANOVA of the quadratic regression model. The value of $F$ (94.426) inferred the corresponding design model to be considerable. $p$-value $<0.05$ states the terms present in the model are important. Coefficient estimates and the resultant values of $P$ imply a linear effect $C, D, E$; the interaction effect $A D, B C, B E$, $C D, D E$ and squared effect $A^{2}, B^{2}, C^{2}, D^{2}$, and $E^{2}$ were found to be highly considerable model conditions for xylanase synthesis.

The model fitness is verified by $R^{2}$. $R^{2}$-value of 0.9848 illustrates the correctness of the model for xylanase production using sugarcane bagasse. The predicted $R^{2}$-value of 0.9423 for xylanase activity is in practical agreement with the adjusted $R^{2}$-values of 0.9744

Adequate precision value, 32 , for xylanase designates a satisfactory signal. A low CV value, 1.45, indicates a superior consistency of the tests executed.

Three-dimensional response surfaces were drawn to explore the combined effects of the experimental parameters and its most favorable intensity on xylanase synthesis. Figures $1-10$ correspond to the most important joint effects of the five experimental parameters and their best possible ranges are explored using $3 \mathrm{D}$ response surface curves.

Figure 1 shows the simultaneous outcome of substrate concentration and temperature on xylanase activity. The nature of the response curves confirms excellent relationships between the above-mentioned variables. The xylanase activity increases, as the

Table 1: Span and extent of experimental parameters.

\begin{tabular}{lcccccc} 
Variables & \multicolumn{7}{c}{ Levels } \\
& Symbolic code & $\mathbf{- 2 . 3 8}$ & $\mathbf{- 1}$ & $\mathbf{0}$ & $\mathbf{1}$ & $\mathbf{2 . 3 8}$ \\
Substrate concentration $(\mathrm{g})$ & $\mathrm{A}$ & 5.2 & 8.0 & 10.0 & 12.0 & 14.8 \\
Temperature $\left({ }^{\circ} \mathrm{C}\right)$ & $\mathrm{B}$ & 29.1 & 32.5 & 35.0 & 37.5 & 40.9 \\
Initial $\mathrm{pH}$ & $\mathrm{C}$ & 2.7 & 4.0 & 5.0 & 6.0 & 7.3 \\
Initial moisture content $(\%)$ & $\mathrm{D}$ & 58.2 & 65.0 & 70.0 & 75.0 & 81.8 \\
Incubation time (hours) & $\mathrm{E}$ & 108.1 & 115 & 120 & 125 & 131.9 \\
\hline
\end{tabular}


Table 2: CCD along with xylanase and CMCase activity as response.

\begin{tabular}{|c|c|c|c|c|c|c|c|c|}
\hline \multirow{2}{*}{ Run No } & \multicolumn{5}{|c|}{ Symbolic coded values } & \multicolumn{2}{|c|}{ Xylanase activity (IU/gds) } & \multirow{2}{*}{$\begin{array}{c}\text { CMCase activity (IU/gds) } \\
\text { Exp }\end{array}$} \\
\hline & $\mathbf{A}$ & B & $\mathbf{C}$ & D & $\mathbf{E}$ & Exp & Pred. & \\
\hline 1 & -1 & -1 & -1 & 1 & -1 & 379.34 & 379.59 & 107.46 \\
\hline 2 & -1 & 1 & 1 & -1 & 1 & 345.65 & 349.17 & 97.92 \\
\hline 3 & -1 & -1 & -1 & -1 & -1 & 368.90 & 369.17 & 104.50 \\
\hline 4 & -1 & 1 & -1 & -1 & 1 & 375.45 & 372.43 & 109.36 \\
\hline 5 & -1 & 1 & 1 & 1 & 1 & 365.09 & 363.71 & 103.42 \\
\hline 6 & 1 & 1 & -1 & -1 & -1 & 331.32 & 335.95 & 96.86 \\
\hline 7 & 0 & -2.38 & 0 & 0 & 0 & 326.43 & 330.49 & 92.47 \\
\hline 8 & 1 & -1 & -1 & 1 & 1 & 305.57 & 307.96 & 82.56 \\
\hline 9 & 0 & 0 & 0 & 0 & -2.38 & 317.04 & 318.25 & 89.81 \\
\hline 10 & -1 & 1 & 1 & -1 & -1 & 317.19 & 307.76 & 89.86 \\
\hline 11 & 1 & 1 & 1 & 1 & -1 & 368.40 & 363.76 & 104.36 \\
\hline 12 & -1 & 1 & -1 & -1 & -1 & 331.03 & 336.07 & 97.78 \\
\hline 13 & 1 & -1 & 1 & 1 & 1 & 336.09 & 328.82 & 95.21 \\
\hline 14 & 0 & 0 & 0 & 0 & 0 & 415.34 & 415.06 & 117.66 \\
\hline 15 & 1 & 1 & 1 & -1 & -1 & 347.90 & 344.39 & 94.56 \\
\hline 16 & 0 & 0 & 2.38 & 0 & 0 & 310.87 & 320.98 & 88.07 \\
\hline 17 & 0 & 0 & 0 & 0 & 0 & 410.23 & 415.06 & 116.21 \\
\hline 18 & -1 & -1 & 1 & -1 & 1 & 342.89 & 336.85 & 97.14 \\
\hline 19 & -1 & 1 & 1 & 1 & -1 & 336.69 & 339.24 & 95.38 \\
\hline 20 & 0 & 2.38 & 0 & 0 & 0 & 356.80 & 358.93 & 101.08 \\
\hline 21 & 0 & 0 & 0 & 0 & 0 & 415.12 & 415.06 & 117.60 \\
\hline 22 & 1 & -1 & 1 & 1 & -1 & 338.31 & 339.90 & 95.84 \\
\hline 23 & -2.38 & 0 & 0 & 0 & 0 & 340.56 & 342.20 & 96.48 \\
\hline 24 & -1 & 1 & -1 & 1 & 1 & 366.14 & 367.32 & 103.72 \\
\hline 25 & 1 & 1 & -1 & -1 & 1 & 373.90 & 369.90 & 108.92 \\
\hline 26 & 0 & 0 & 0 & 0 & 0 & 415.34 & 415.06 & 117.66 \\
\hline 27 & 1 & -1 & -1 & -1 & 1 & 324.65 & 326.60 & 97.97 \\
\hline 28 & -1 & -1 & 1 & -1 & -1 & 327.45 & 328.59 & 92.76 \\
\hline 29 & 0 & 0 & 0 & 0 & 0 & 414.24 & 415.06 & 117.35 \\
\hline 30 & 0 & 0 & 0 & 0 & 0 & 415.09 & 415.06 & 117.59 \\
\hline 31 & 0 & 0 & 0 & 0 & 2.38 & 343.35 & 348.33 & 97.27 \\
\hline 32 & 0 & 0 & 0 & 0 & 0 & 415.45 & 415.06 & 117.69 \\
\hline 33 & 1 & 1 & -1 & 1 & 1 & 355.78 & 352.68 & 100.79 \\
\hline 34 & 1 & 1 & 1 & 1 & 1 & 383.60 & 385.81 & 108.67 \\
\hline 35 & 0 & 0 & 0 & -2.38 & 0 & 345.06 & 351.88 & 97.75 \\
\hline 36 & -1 & -1 & 1 & 1 & -1 & 358.90 & 358.65 & 101.67 \\
\hline 37 & -1 & -1 & -1 & -1 & 1 & 375.34 & 372.39 & 106.33 \\
\hline 38 & 1 & -1 & -1 & -1 & -1 & 332.56 & 325.79 & 94.21 \\
\hline 39 & 0 & 0 & 0 & 0 & 0 & 415.21 & 415.06 & 117.62 \\
\hline 40 & -1 & -1 & -1 & 1 & 1 & 360.98 & 365.86 & 102.26 \\
\hline 41 & 0 & 0 & 0 & 2.38 & 0 & 367.78 & 367.15 & 104.19 \\
\hline 42 & 1 & 1 & -1 & 1 & -1 & 331.32 & 335.67 & 93.86 \\
\hline 43 & 1 & -1 & -1 & 1 & -1 & 325.67 & 324.09 & 92.26 \\
\hline 44 & 1 & -1 & 1 & -1 & 1 & 327.45 & 327.82 & 92.76 \\
\hline 45 & -1 & 1 & -1 & 1 & -1 & 352.25 & 347.90 & 99.79 \\
\hline 46 & 0 & 0 & -2.38 & 0 & 0 & 333.76 & 329.84 & 94.55 \\
\hline 47 & 2.38 & 0 & 0 & 0 & 0 & 312.34 & 316.89 & 88.48 \\
\hline 48 & -1 & -1 & 1 & 1 & 1 & 355.45 & 349.97 & 100.69 \\
\hline 49 & 1 & -1 & 1 & -1 & -1 & 324.27 & 321.96 & 91.86 \\
\hline 50 & 1 & 1 & 1 & -1 & 1 & 388.67 & 383.39 & 110.10 \\
\hline
\end{tabular}

Std. Dev $=5.1715 ; R^{2}=0.9848 ;$ Mean $=356.48 ;$ Adj $R^{2}=0.9744 ;$ C.V $=1.45 ;$ Pred $R^{2}=0.9423 ;$ Adeq Precision $=32.00$. 

using inexpensive agro-industrial waste 2021;9(05):157-165

Table 3: ANOVA for xylanase production using sugarcane bagasse.

\begin{tabular}{|c|c|c|c|c|c|c|}
\hline Source & Coeffestimate & Sum of squares & df & Mean squares & Fvalue & $p$-value Prob $>F$ \\
\hline Model & 415.017 & $50,509.087$ & 20 & $2,525.4544$ & 94.4261 & $<0.0001$ \\
\hline A & -5.3185 & $1,225.6110$ & 1 & $1,225.6110$ & 45.8253 & $<0.0001$ \\
\hline$B$ & 5.9739 & $1,546.2800$ & 1 & $1,546.2800$ & 57.8150 & $<0.0001$ \\
\hline C & -1.8620 & 150.2228 & 1 & 150.2228 & 5.6168 & 0.0247 \\
\hline$D$ & 3.2088 & 446.1315 & 1 & 446.1315 & 16.6807 & 0.0003 \\
\hline E & 6.3195 & $1,730.4007$ & 1 & $1,730.4007$ & 64.6992 & $<0.0001$ \\
\hline$A B$ & 10.8150 & $3,742.8552$ & 1 & $3,742.8552$ & 139.9444 & $<0.0001$ \\
\hline$A C$ & 9.1888 & $2,701.8601$ & 1 & $2,701.8601$ & 101.0219 & $<0.0001$ \\
\hline$A D$ & -3.0288 & 293.5465 & 1 & 293.5465 & 10.9756 & 0.0025 \\
\hline$A E$ & -0.6025 & 11.6162 & 1 & 11.6162 & 0.4343 & 0.5151 \\
\hline$B C$ & 3.0688 & 301.3513 & 1 & 301.3513 & 11.2674 & 0.0022 \\
\hline$B D$ & 0.3550 & 4.0328 & 1 & 4.0328 & 0.1508 & 0.7006 \\
\hline$B E$ & 8.2863 & $2,197.1821$ & 1 & $2,197.1821$ & 82.1521 & $<0.0001$ \\
\hline$C D$ & 4.9113 & 771.8520 & 1 & 771.8520 & 28.8594 & $<0.0001$ \\
\hline$C E$ & 1.2613 & 50.9040 & 1 & 50.9040 & 1.9033 & 0.1783 \\
\hline$D E$ & -4.2363 & 574.2661 & 1 & 574.2661 & 21.4717 & $<0.0001$ \\
\hline$A^{2}$ & -15.0889 & $12,679.284$ & 1 & $12,679.284$ & 474.0753 & $<0.0001$ \\
\hline$B^{2}$ & -12.4116 & $8,579.0319$ & 1 & $8,579.0319$ & 320.7678 & $<0.0001$ \\
\hline$C^{2}$ & -15.8189 & $13,935.808$ & 1 & $13,935.808$ & 521.0563 & $<0.0001$ \\
\hline$D^{2}$ & -9.7979 & $5,346.2539$ & 1 & $5,346.2539$ & 199.8951 & $<0.0001$ \\
\hline$E^{2}$ & -14.4277 & $11,592.494$ & 1 & $11,592.494$ & 433.4404 & $<0.0001$ \\
\hline Residual & & 775.6137 & 29 & 26.7453 & & \\
\hline Lack of fit & & 753.7629 & 22 & 34.2620 & 10.9760 & 0.0016 \\
\hline Pure error & & 21.8508 & 7 & 3.1215 & & \\
\hline Corr total & & $51,284.701$ & 49 & & & \\
\hline
\end{tabular}

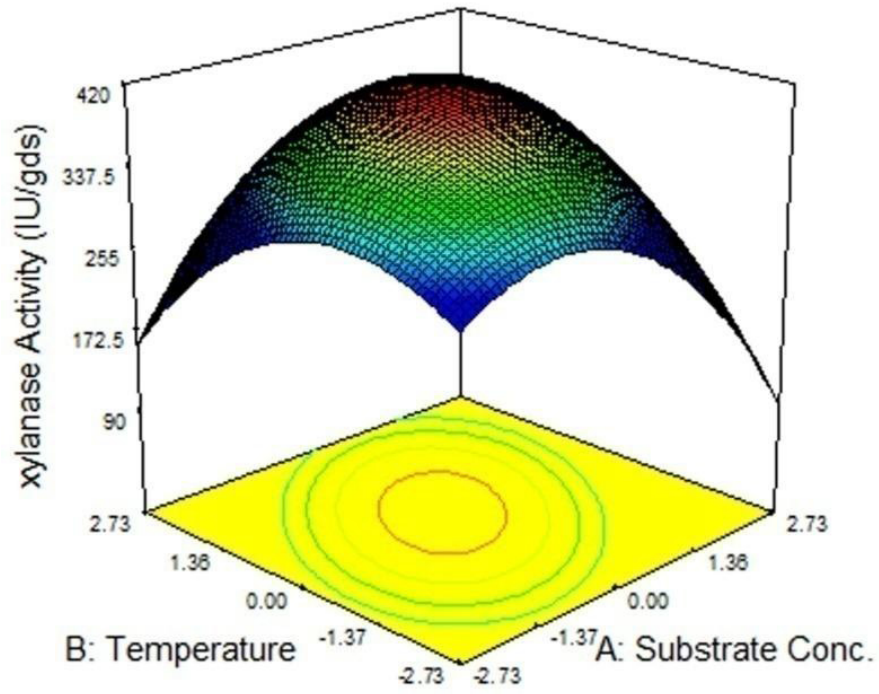

Figure 1: Three-dimensional simultaneous effect plot of substrate concentration and temperature.

substrate concentration increases, and reaches maximum activity at $9.88 \mathrm{~g}$ of substrate. Thereafter, the xylanase activity decreases. This may be owing to the reality that elevated concentrations of substrate leads to an increase in stickiness of the medium, which affects the constituents present in the medium and the transportation

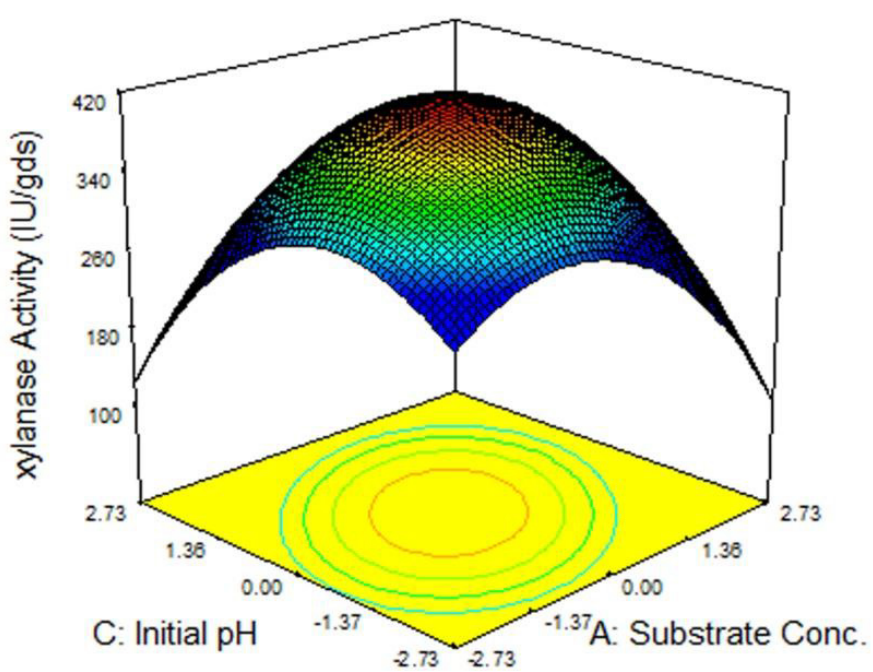

Figure 2: Three-dimensional simultaneous effect plot of substrate concentration and initial $\mathrm{pH}$.

of oxygen to the cells through substrate gets decreased due to poor aeration rate [19]. This is evident from Figures 2-4.

The consequence of temperature on xylanase activity is investigated by carrying out experiments at different temperatures 


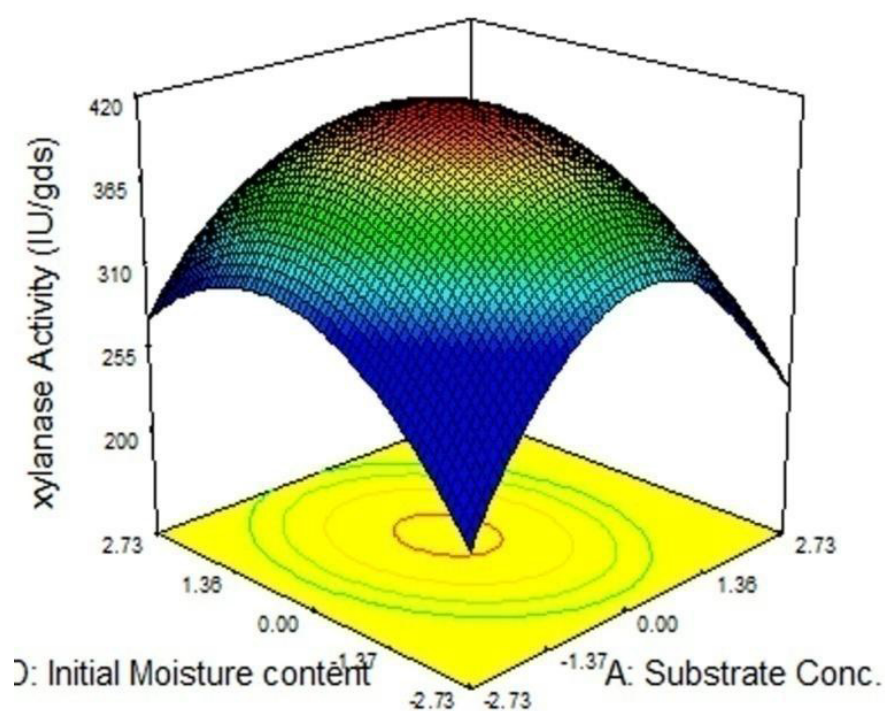

Figure 3: Three-dimensional simultaneous effect plot of substrate concentration and Initial moisture content.

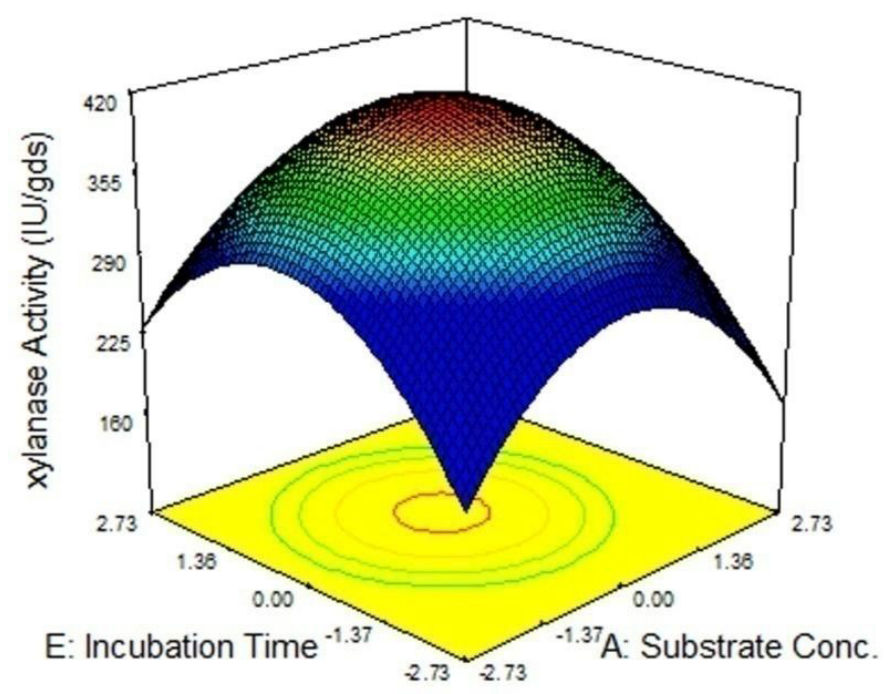

Figure 4: Three-dimensional simultaneous effect plot of substrate concentration and incubation time.

starting from $29.1{ }^{\circ} \mathrm{C}$ to $40.9^{\circ} \mathrm{C}$. The results are shown in Figures 1, 5, 6 and 7. An increase in xylanase activity could be achieved when the value of temperature is increased from $29.1^{\circ} \mathrm{C}$ to $40.9^{\circ} \mathrm{C}$. The temperature perhaps increases the secretion of the enzyme by altering the properties of the cell wall of the fungi [20]. The xylanase activity decreased considerably even for slight increase in the temperature from $35.73^{\circ} \mathrm{C}$.

The consequence of initial $\mathrm{pH}$ on xylanase activity is studied by conducting experiments from $\mathrm{pH} 2.7$ to 7.3 , and the results are shown in Figures 2, 5, 8, and 9. The maximum xylanase activity was obtained at $\mathrm{pH} 4.98$. This indicates that A. fumigatus was resistant to acidic operating conditions. At this $\mathrm{pH}$ value, high xylanase activities were obtained when compared to that for other $\mathrm{pH}$ values which also confirms a usual profile of an acidophilic

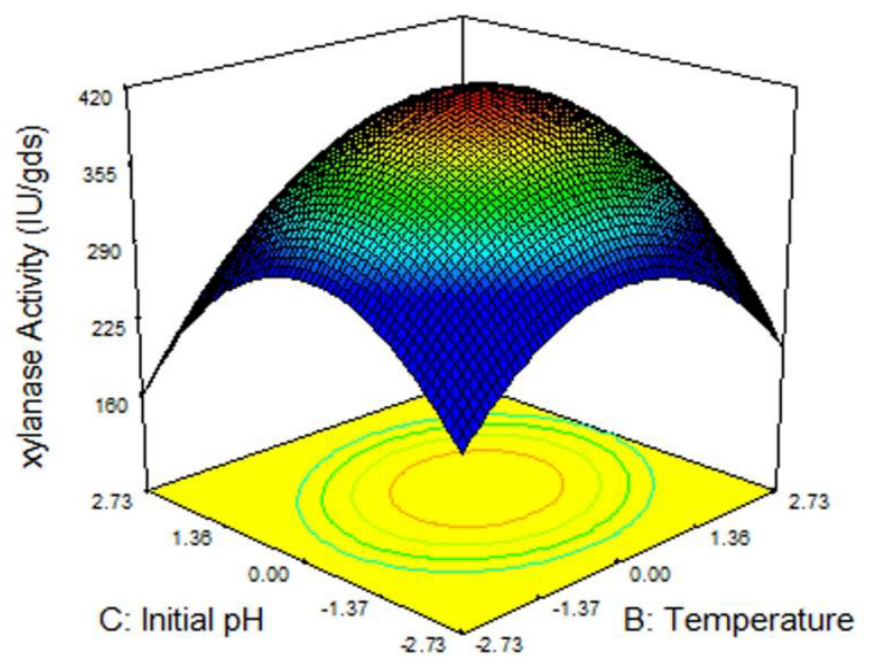

Figure 5: Three-dimensional simultaneous effect plot of temperature and initial $\mathrm{pH}$.

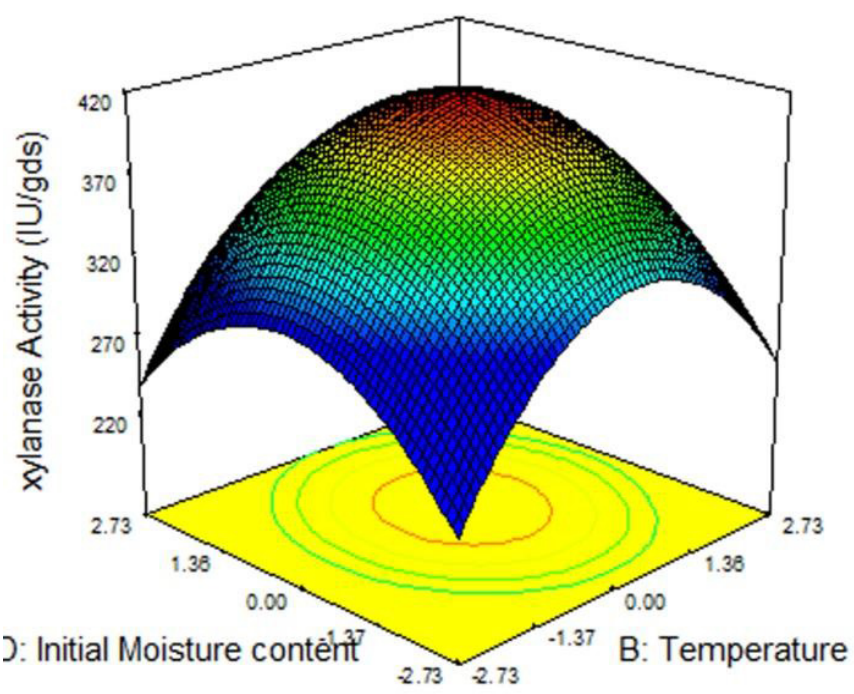

Figure 6: Three-dimensional simultaneous effect plot of temperature and initial moisture content.

enzyme [21]. However, the xylanase activity decreases when the $\mathrm{pH}$ is raised above 4.98. Cultivation of the microorganism at adverse $\mathrm{pH}$ restricts the growth of fungi, xylanase production, and accessibility of the substrate.

The consequence of the initial moisture content on xylanase activity is studied by carrying out experiments ranging from $58.2 \%$ to $81.8 \%$. The results are revealed in Figures 3, 6, 8, and 10. The enzyme activity was found to increase as initial moisture content is elevated from $71.2 \%$ to $76.1 \%$, and it was found to decrease with further increase in moisture percentage of the medium. The maximum activity of $415.45 \mathrm{IU} / \mathrm{gds}$ xylanase activity was attained with the initial moisture content of $71.30 \%$. The decrease in the enzyme activity for initial moisture content greater than $71.30 \%$ might be due to the fact that higher wetness intensity time and again 


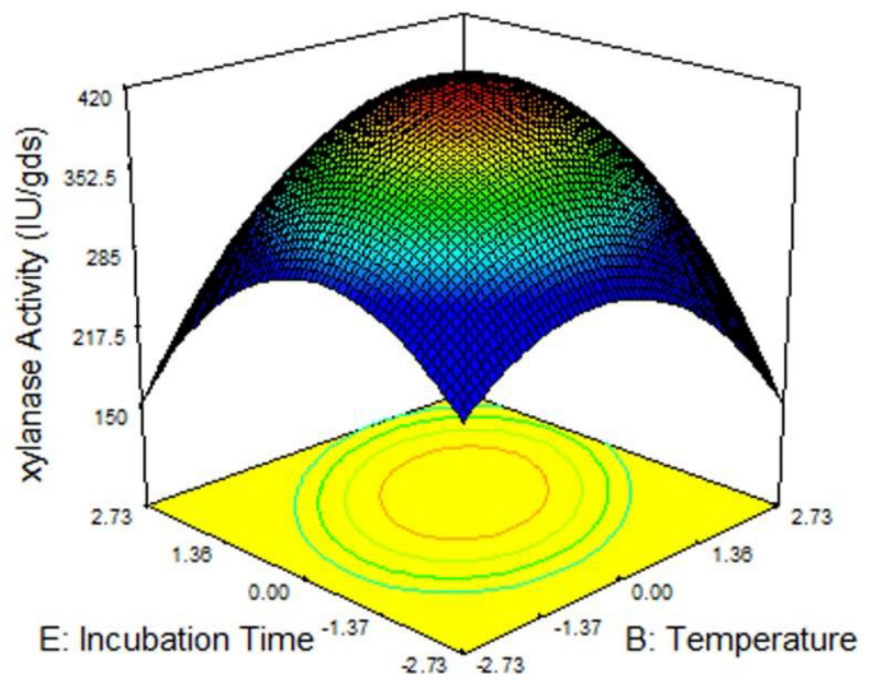

Figure 7: Three-dimensional simultaneous effect plot of temperature and incubation time.

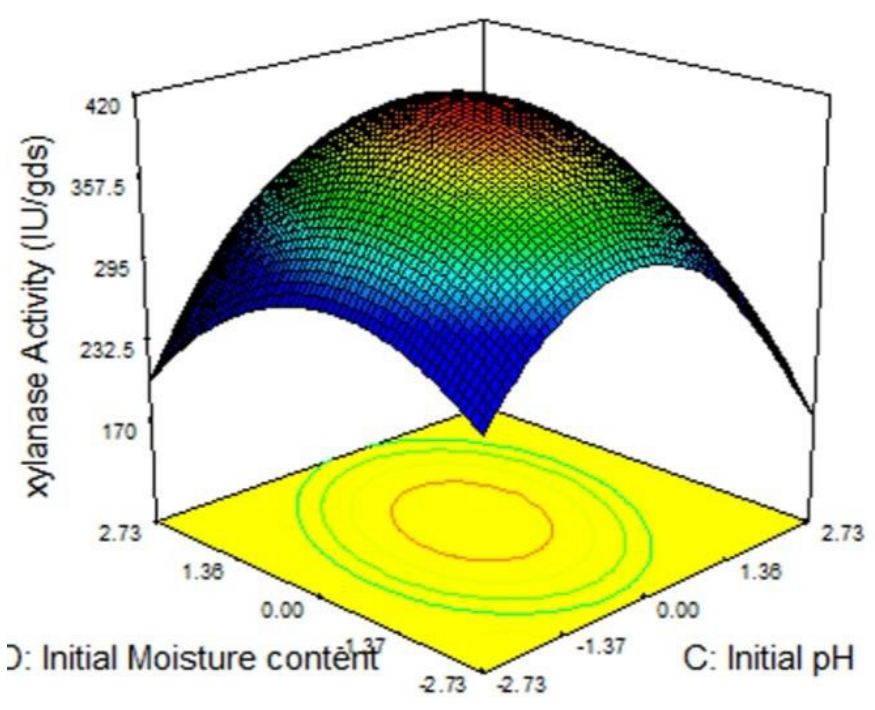

Figure 8: Three-dimensional simultaneous effect plot of initial $\mathrm{pH}$ and initial moisture content.

guides to constituents of sugarcane bagasse attaching together to the flask which reduced porosity of substrate and preventing the transfer of oxygen into the substrate as a barrier. Moreover, high moisture occupies the spaces between the particles not allowing oxygen and formulates the medium to be further susceptible to bacterial infection [22].

The consequence of incubation time on xylanase activity is investigated by conducting experiments with incubation period ranging from 108.1 to 131.9 hours, which are shown in the Figures 4, 7, 9, and 10. The maximum xylanase of $415.45 \mathrm{IU} / \mathrm{gds}$ is obtained with the incubation period of 120.05 hours. Additional increase in incubation time results in the decline of xylanase activity. This might be due to the decrease in the exhaustion of the constituents present in the medium that leads to decreased

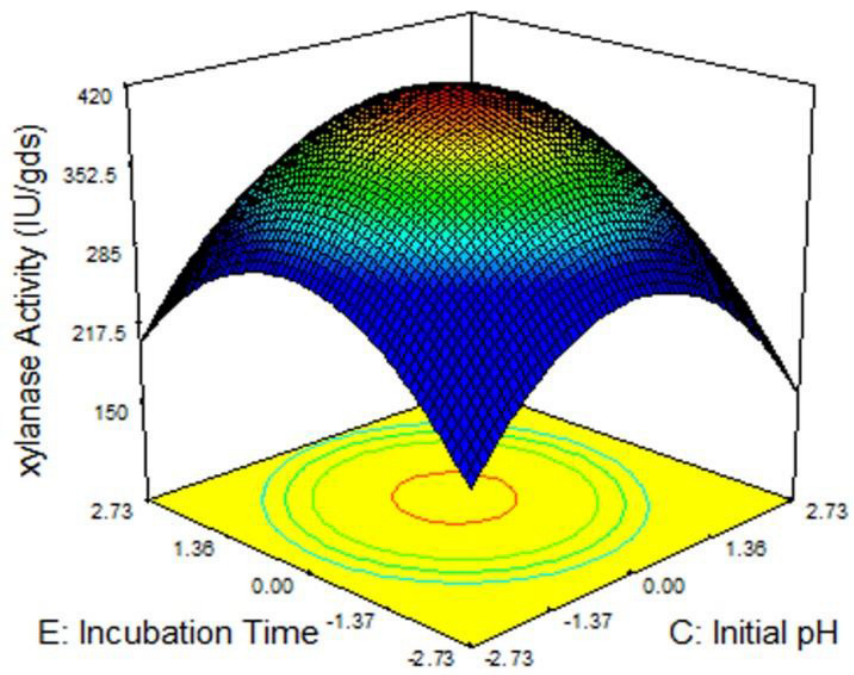

Figure 9: Three-dimensional simultaneous effect plot of $\mathrm{pH}$ and incubation time.

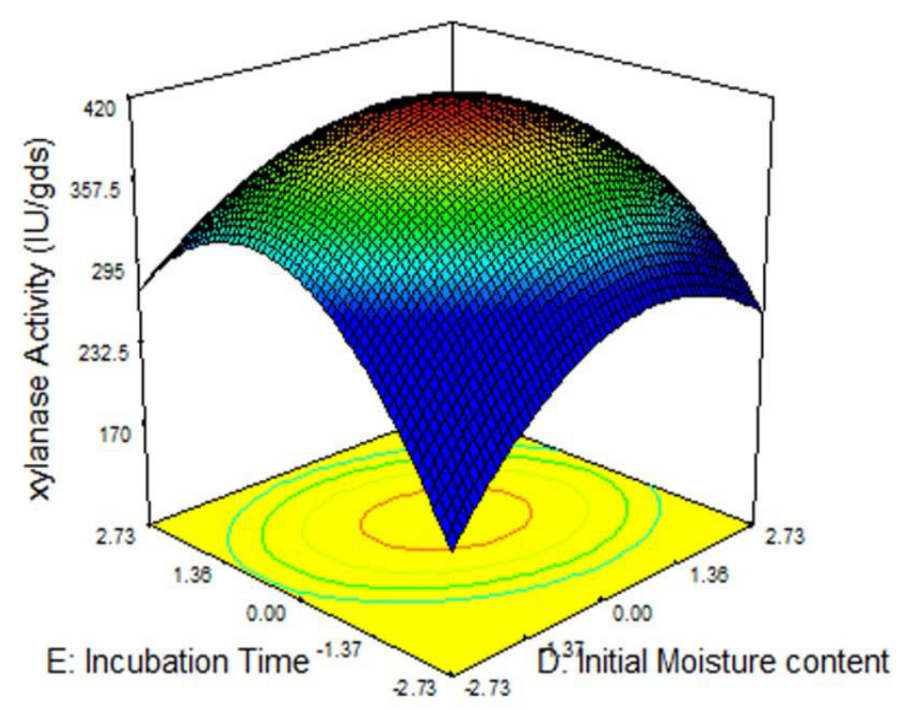

Figure 10: Three-dimensional simultaneous effect plot of initial moisture content and incubation time.

growth of the cells as well as enzyme production. With prolonged incubation, the decrease in enzyme activity could be appropriate to the fact that xylanases are frequently articulated at the closing stages of the exponential phase and yielding period is related to the medium under consideration [23].

Optimum conditions are the lone points from where the highest xylanase activity is achieved. By solving Eq. (3) using RSM, the most favorable situation for production of xylanase enzyme is acquired. The most favorable experimental values of the tested variables for highest xylanase activity are substrate concentration $=9.88 \mathrm{~g}$, temperature $=35.73^{\circ} \mathrm{C}, \mathrm{pH}=4.98$, initial moisture content $=71.30 \%$, and incubation time $=120.05$ hours. The most favorable values for the parameters as predicted are within the design region. Figure 11 confirms the experimental values be in 


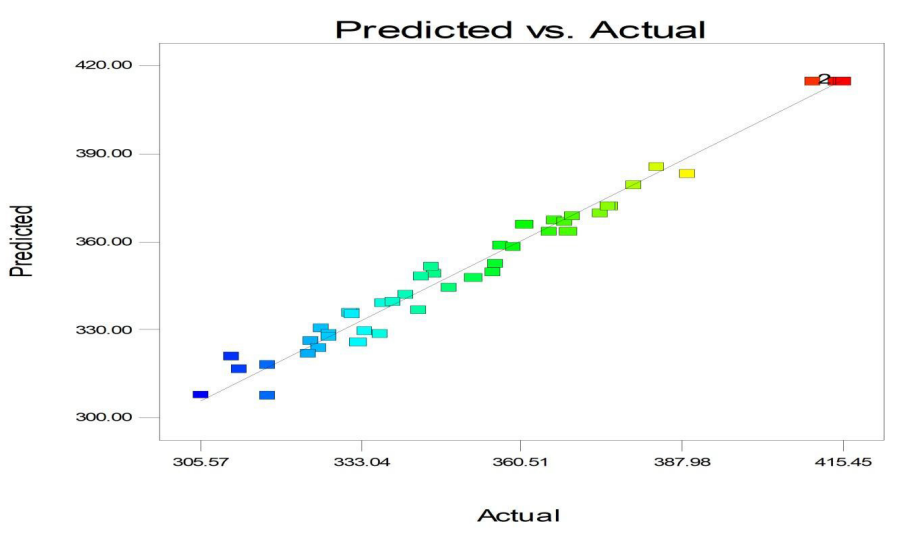

Figure 11: Predicted versus experimental xylanase activity.

agreement with the predicted values. Very poor CMCase activity is also found along with xylanase production.

Using Aspergillus sp. under SSF, the optimum values for substrate concentration, temperature, initial $\mathrm{pH}$, initial moisture content, and incubation time for maximum xylanase activity as reported by previous studies [24-28] were $10 \mathrm{~g}, 35^{\circ} \mathrm{C}^{\circ}, 3.5-5.5,70 \%-72 \%$, and 100-120 hours, respectively, which are in excellent agreement with the present research data also.

\subsection{Model Validity}

Validity of the model is checked by conducting the group experimentation under more favorable operating circumstances. After conducting three repetitive experiments, the xylanase activities are compared. The experimental xylanase activity is found to be $417.501 \mathrm{IU} / \mathrm{gds}$, which is very close to that of 417.121 $\mathrm{IU} / \mathrm{gds}$, predicted by the regression model. Also it confirms the model validity.

\section{CONCLUSION}

The optimization of xylanase production using inexpensive agricultural waste under cheaper SSF technology by RSM was investigated in the current research. The usage of sugarcane bagasse as low-cost agro-wastes brought down the xylanase enzyme production cost and also reduces environmental pollution. To formulate xylanase production, further cost-effective, experimental parameters optimization were carried out through RSM. Enhanced xylanase activity of $417.501 \mathrm{IU} / \mathrm{gds}$ was obtained with the following optimum process parameters: substrate concentration $=9.88 \mathrm{~g}$, temperature $=35.73^{\circ} \mathrm{C}$, initial $\mathrm{pH}=4.98$, initial moisture content $=71.31 \%$, and incubation time $=120.05$ hours. It is concluded that SSF technique using inexpensive agrowaste (sugarcane bagasse) as substrate was more effective, as well as economical, for production of xylanase by $A$. fumigatus.

\section{ACKNOWLEDGMENTS}

The authors express their deep sense of gratefulness for the support granted by the authorities in carrying out the research work in Bioprocess Laboratory, Department of Chemical Engineering, FEAT, Annamalai University.

\section{CONFLICTS OF INTEREST}

The authors state that they do not have any conflicts of interest.

\section{FUNDING}

None.

\section{REFERENCES}

1. Pinotti LM, Lacerda JX, Olivseira MM, Teixeira RD, Rodrigues C, Cassini STA. Production of lipolytic enzymes using agro-industrial residues. Chem Eng Trans 2017;56:1897-902.

2. BCC-Research, Global Markets for Enzyme in Industrial Application, BCC Research, Wellesley, MA, 2020. Available via https://www. bccresearch.com/market-search/biotechnology/global-marketsforenzymes-in-industrial-applications.html [(CitedAccessed 20 January 2020 Jan 20]).

3. Chadha BS, Kaur B, Basotra N, Tsang A, Pandey A. Thermostable xylanases from thermophilic fungi and bacteria: current perspective. Bioresour Technol 2019;277:195-203.

4. Ho HL, Lau LY. Bioprocessing of agricultural wastes as optimised carbon source and optimisation of growth conditions for xylanase production by Aspergillus brasiliensis in agitated solid state fermentation (Ssf). J Biodivers Bioprocess Dev 2014;1:125-36.

5. Chakrit T, Khin LK, Khanok R. Purification of xylanase from alkaliphilic Bacillus sp. $K-8$ by using corn husk column. Process Biochem 2006;41(12):2441-5.

6. Yang W, Yang Y, Zhang L, Xu H, Guo X, Yang X, et al. Improved thermostability of an acidic xylanase from Aspergillus sulphureus by combined disulphide bridge introduction and proline residue substitution. Sci Rep 2017;7:1587; doi:10.1038/s41598-017-01758-5

7. Bilgrami KS, Pandy AK. In: Jain ESK (ed.). Chapter title-15. Industry and Fermentations, CBS Publishers \& Distributors PVT. LTD, New Delhi, India, pp 149-65, 1992.

8. Marimuthu M, Sorimuthu A, Muruganantham S. Production and optimization of xylanase enzyme from bacillus subtilis using agricultural wastes by solid state fermentation. Int J Pharm Investig 2019;9(4):169-73.

9. Richhariya J, Sharma TK, Dassani S. Production and optimization of enzyme xylanase by Aspergillus flavus using agricultural waste residues. J Appl Biol Biotech 2020;8(4):082-9.

10. Techapun C, Poosaran N, Watanabe M, Sasaki K. Optimization of aeration and agitation rates to improve cellulose-free xylanase production by thermotolerant Streptomyces sp. Ab106 and repeated fed-batch cultivation using agricultural waste. J Biosci Bioeng 2003;95:298-301.

11. Rashid R, Ejaz U, Ali FI, Hasmi IA, Bari A, Liu J, et al. Combined pretreatment of sugarcane bagasse using alkali and ionic liquid to increase hemicellulose content and xylanase production. BMC Biotechnol 2020;20:64; doi:10.1186/s12896-020-00657-4

12. Motta FL, Andrade CCP, Santana MHA. A review of xylanase production by the fermentation of xylan: classification, characterization and applications. Sustainable degradation of lignocellulosic biomasstechniques, applications and commercialization. InTechOpen, New York, NY, pp 251-75, 2013.

13. Kumar A, Gautam A, Dutt D. Screening of fungal resources for the production of cellulases and xylanases. Br Biotechnol J 2015;9(1):1-13.

14. Khanahmadia M, Arezia I, Amiri M, Miranzadeh M. Bioprocessing of agro-industrial residues for optimization of xylanase production by solid state fermentation in flask and tray bioreactor. Biocatal Agric Biotechnol 2018;19:272-82.

15. Sunkar B, Kannoju B, Bhukya B. Optimized production of xylanase by Penicillium purpurogenum and ultrasound impact on enzyme kinetics for the production of monomeric sugars from pretreated corn cobs. Front Microbiol 2020;11:772; doi:10.3389/fmicb.2020.00772 
16. Khusro A, Kaliyan BK, Al-Dhabi NA, Arasu MV, Agastian P. Statistical optimization of thermo-alkali stable xylanase production from Bacillus tequilensis strain ARMATI. Electron J Biotechnol 2016;22:16-25.

17. Cui F, Zhao L. Optimization of xylanase production from Penicillium sp.WX-Z1 by a two-step statistical strategy: Plackett-Burman and Box-Behnken experimental design. Int J Mol Sci 2012;13:10630-46.

18. Miller GL. Use of dinitrosalicylic acid reagent for determination of reducing sugar. Anal Chem 1959;31:426-8.

19. Norazlina I, Meenalosani N, Halim K. Production of xylanase by Trichoderma $s p$. via solid state culture using sugarcane bagasse. Int $\mathrm{J}$ Energy Sci 2013;3(2):99-105.

20. Anandan D, Marmer WN, Dudley RL. Isolation, characteriza-tion and optimization of culture parameters for production of an alkaline protease isolated from Aspergillus tamari. J Ind Microbiol Biotechnol 2007;34(5):339-34.

21. Gomes AFS, Lamanes BS, Manuele DS, Milla GF, Baffi A. Substrate and temperature effect on xylanase production by Aspergillus fumigatus using low cost agricultural wastes. Biosci J Uberlândia 2016;32(4):915-21.

22. Lonsane BK, Ghildyal NP, Budiatman S, Ramakrishna SV. Engineering aspects of solid state fermentation. Enzyme Microbiol Technol 1985; 7:258-65.

23. Kulkarni N, Mala Rao A, Molecular and biotechnological aspects of xylanases. FEMS Microbiol Rev 1999;23:411-56.

24. Sandrim VC, Rizzatti ACS, Terenzi HF, Jorge JA, Milagres AMF. Purification and biochemical characterization of two xylanases produced by Aspergillus caespitosus and their potential for kraft pulp bleaching. Process Biochem 2005;40:1823-8.

25. Widjaja A, Lestari E, Tanjung A, Alfian W, Ogino H. Optimized production of xylanase from fungal strains and its purification strategies. J Appl Sci Environ San 2009;4:219-32.

26. Cunha CCQB, Campos ITN, Faria FP, Bataus LAM. Screening and xylanase production by Streptomyces $s p$. grown on lignocellulosic wastes. Appl Biochem Biotechnol 2013; 170(3):598-608.

27. Moretti MMS, Bocchini MDA, Silva R, Rodrigues A, Sette LD, Gomes E. Selection of thermophilic and thermotolerant fungi for the production of cellulases and xylanases under solid state fermentation. Braz J Microbiol 2012;43:1062-71.

28. Singh J, Kumar A, Singh S, Singh F, Manmohan. Effect of substrate and moisture content on mycelia growth of Ganoderma lucidum (Leyss. Ex.Fr) karst. Int J Agric Sci Res 2017;7(1):183-6.

\section{How to cite this article:}

Kanagasabai V, Maruthai K. Optimization of process and conditions for enhanced xylanase production under SSF using inexpensive agro-industrial waste. J Appl Biol Biotech 2021; 9(05):157-165. 